\title{
An IOT-Enabled Generator for Power Monitoring and Load Management with Power Factor Improvement ${ }^{\dagger}$
}

\author{
Ghulam Shabir Memon *, Syed Saeed Jaffer, Shoaib Zaidi, Muhammad Mohsin Sheikh, Muhammad Umair Jabbar \\ and Abdul Ahad
}

Citation: Memon, G.S.; Jaffer, S.S.; Zaidi, S.; Sheikh, M.M.; Jabbar, M.U.; Ahad, A. An IOT-Enabled Generator for Power Monitoring and Load Management with Power Factor Improvement. Eng. Proc. 2021, 12, 33. https://doi.org/10.3390/ engproc2021012033

Academic Editor: Nazam Siddique

Published: 24 December 2021

Publisher's Note: MDPI stays neutral with regard to jurisdictional claims in published maps and institutional affiliations.

Copyright: (C) 2021 by the authors. Licensee MDPI, Basel, Switzerland. This article is an open access article distributed under the terms and conditions of the Creative Commons Attribution (CC BY) license (https:// creativecommons.org/licenses/by/ $4.0 /)$.
Department of Electrical Engineering, Indus University, Karachi 75300, Pakistan; saeed.jaffer@indus.edu.pk (S.S.J.); shoaib.hussain@indus.edu.pk (S.Z.); muhammad.mohsin@indus.edu.pk (M.M.S.); Umairjabbar1491@gmail.com (M.U.J.); abdulahad_aa@outlook.com (A.A.)

* Correspondence: shabir.memon@indus.edu.pk

† Presented at the 1st International Conference on Energy, Power and Environment, Gujrat, Pakistan, 11-12 November 2021.

\begin{abstract}
The quality of power supply and reliability play a vital role in the smooth operation and maintenance of commercial use. These requirements have significant applications when dealing with residential areas, hospitals, industries, educational sectors, banks and airports, etc. In this regard, backup diesel generators are considered the most important source for an uninterrupted supply of electricity. However, there is an emergent need to avoid sudden shutdown of generators in the events of overload, shortage of fuel flow, service interval and lagging of power factor. These common problems can be addressed through monitoring of power generator parameters, for instance, real time remote monitoring to measure the health of the generator, the problem of load management due to high demand of power during peak hours and power factor improvement due to exceeding inductive load. In this paper, our proposed architecture-based on an IOT solution-consists of different sensors, namely a current transformer for measuring load, fuel gauge for fuel level monitoring, and temperature measurement with the energy module to determine the power factor of the system. Our proposed system is operated and tested on a real trolley-mounted 25 KVA generator.
\end{abstract}

Keywords: IOT; power factor; inductive load; Arduino and uninterrupted power supply

\section{Introduction}

The use of power system is considered an essential and basic amenity to supply electricity to consumers without any interruption [1]. This power supply actually provides the platform to the next industrial revolution 4.0. The reliability and the continuity of power supply is the futuristic need of all verticals of industry [2]. In any commercial power supply system, the power grid stations are used as the main source of power supply; however, sometimes due to a shortage of energy resources or the vulnerability of the system, the five nine availability of continuous power supply is not available, especially in the underdeveloped countries such as Pakistan [3,4]. To address this problem, one of the possible solutions presented in the literature is the use of a diesel generator. Therefore, these backup generators are always considered the primary backup source at all times in the absence of the main supply [5-7].

The basic architecture of the (IoT) system is illustrated in Figure 1.

The actual power factor of the inductive load varies from 50 to $60 \%$. However, in this paper, we have maintained a power factor value above $90 \%$ to maintain efficiency of the system. The rest of the paper is defined as follows. Section 2 describes the proposed architecture of the system, whereas Section 3 discusses the obtained results in Arduino Mega (2560) open-based software, while Section 4 concludes the paper. 


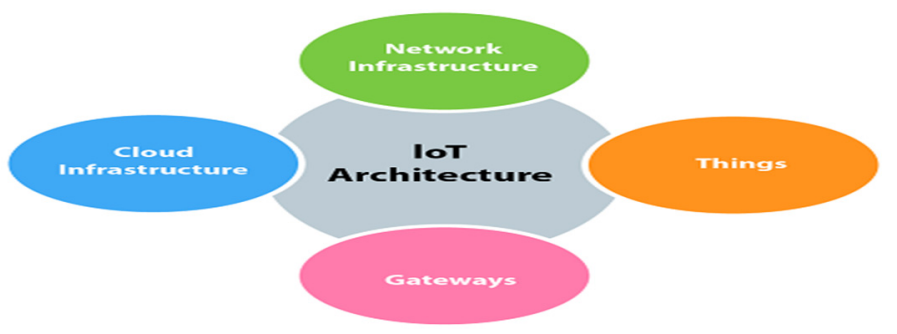

Figure 1. Basic architecture (IoT).

\section{System Model and Description}

This concept begins with the interfacing of an Arduino Mega controller, which is controlling all the functions of the generator, with the allied hardware module for the real-time monitoring of data as illustrated in the Figure 2.

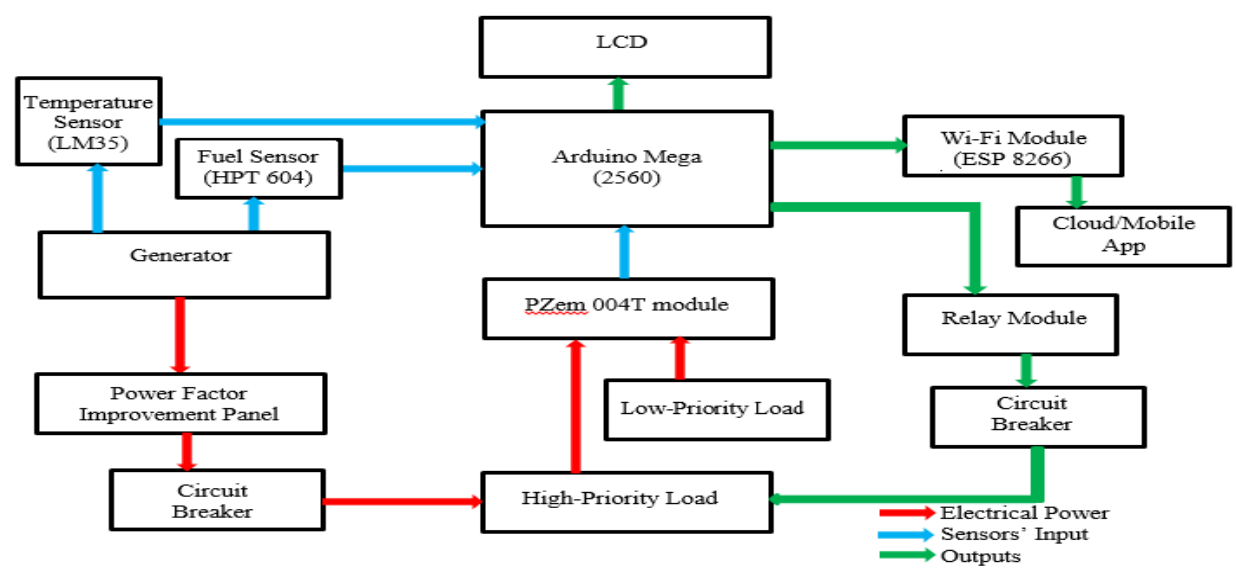

Figure 2. Basic architecture of proposed system.

The proposed architecture has monitored the following parameters of the $25 \mathrm{KV}$ generator; for instance, we have employed the PZEM 004T module which is responsible for giving values of voltage, current, power, frequency, energy and power factor of the load currently delivered by the generator. We have used its latest version, V3, which has an ampere rating of $100 \mathrm{~A}$.

The proposed system also used the LM35 to measure the temperature (thermal characteristic) of the generator; the sensor gives analog output which is proportional to the temperature with greater accuracy as compared to thermistors and other temperature sensors. This temperature sensor does not need any calibration, and therefore has the tendency to resist against self-heating, whereas to measure the fuel level a HPT 604-fuel sensor is used.

In the proposed system an ESP 8266 module is also used, which is responsible for sending data to the $\mathrm{i}$-cloud so that we can remotely monitor the parameters of the generator. This module is widely used by researchers in IoT-based application.

\section{Results and Discussion}

The obtained results are described by means of graphs and taken from commercially available software. We have analyzed the performance of the proposed architecture in terms of different parameters related to load management, fuel level and temperature and power factor for real-time monitoring.

\subsection{Thermal Analysis}

This Figure 3 clearly shows that temperature increases with its running time. Our designed smart IoT-based system continuously measured the rise in temperature and 
reported it to the cloud. This time reporting will help the operator to avoid severe damage to the system as well as the monitor other performance of system.

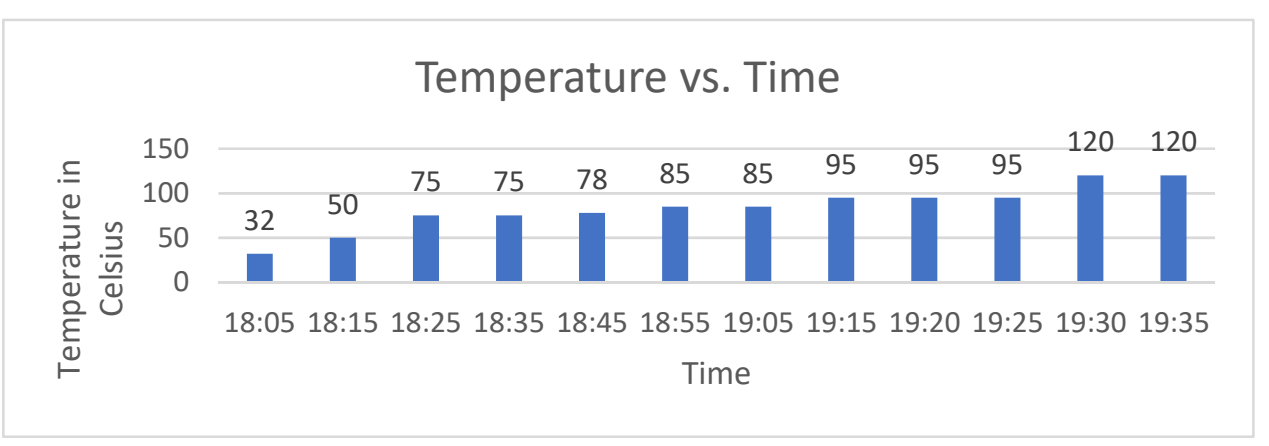

Figure 3. Change in temperature.

\subsection{Power Factor Analysis with and without Capacitive Bank}

Figure 4 shows the graph of the power factor range value from 0 to 1 versus time. This analysis is based on the load value connected to the generator output side. We have obtained results with and without the capacitive bank. The desired result was obtained by applying the capacitive bank with the load in order to achieve unity gain. This result avoided an increase in reactive power, power losses, fuel consumption and overload.

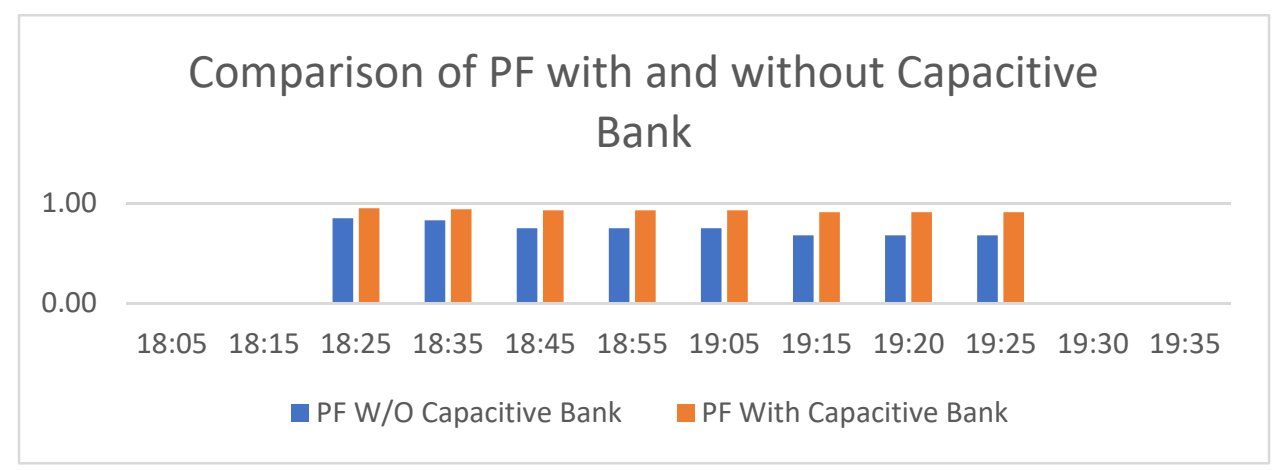

Figure 4. Power factor correction comparison.

\subsection{Analysis of Consumed Power in Terms of System Load}

The graph shown in Figure 5 monitored zero at the start of the time interval and slightly varied as the load increased with respect to time. This analysis is helpful in order to manage load and avoid unnecessary shutdown.

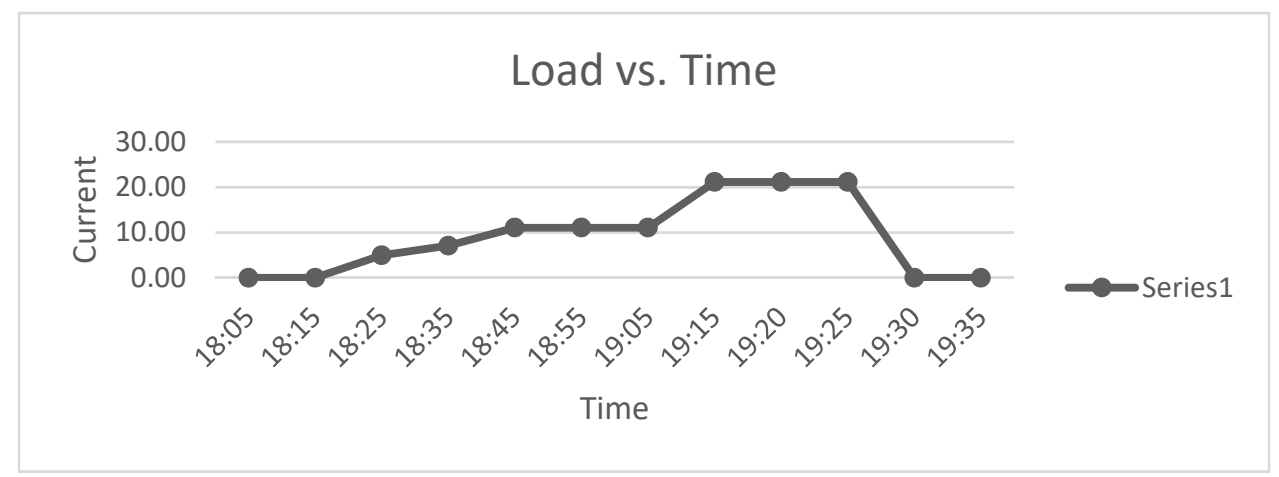

Figure 5. Consumed power of connected load. 


\section{Conclusions}

Our results conclude that the proposed approach of monitoring, controlling and reporting the backup supply system through the Arduino-based controller is a performanceefficient and cost-effective solution to small-scale industry application as well as the other verticals of the industry. The study also shows that controlling the alarms directly to the cloud or to the remote end can reduce the OPEX cost of the system substantially. However, for future work we plan to evaluate the suitability of our proposed system in terms of reliability versus cost analysis in more complex scenarios, for instance in a large geographical area. This analysis may further help us to understand our approach better for a large-scale power supply system.

Author Contributions: Idea Conceptualization, G.S.M.; Write up and Proof Rearding, S.S.J.; Data Analysis and Simulation, S.Z.; Hardware Design, M.M.S. and M.U.J.; Data Monitoring, A.A. All authors have read and agreed to the published version of the manuscript.

Conflicts of Interest: The authors declare no conflict of interest.

\section{References}

1. Khan, M.A.; Waqas, A.; Khand, Q.U.; Khan, S. Context Aware Fuel Monitoring System for Cellular Sites. Int. J. Adv. Comput. Sci. Appl. 2017, 8, 281-285.

2. Obikoya, G.D. Design, construction, and implementation of remote fuellevel monitor system. EURASIP J. Wirel. Commun. Netw. 2014, 1, 76. [CrossRef]

3. Khan, S.R.; Ferdousi, A.; Khan, S.R. Real Time Generator Fuel Level Measurement Meter Embedded with Ultrasound Sensor and Data Acquisition System. J. Autom. Control Eng. 2013, 1, 1-7. [CrossRef]

4. Goundar, J.A.; Chand, A.A.; Tabua, N.; Prasad, R.; Chand, P.; Metha, U.; Mamun, K.A. Mechatronic design solution for fuel level monitoringusing pressure sensor. In Proceedings of the Asia-Pacific World Congress on Computer Science and Engineering, Nadi, Fiji, 4-5 November 2014.

5. Ahmed, A.A.I.; Mohammed, S.A.E.; Satte, M.A.M.H. Fuel management system. In Proceedings of the 2017 International Conference on Communication, Control, Computing and Electronics Engineering (ICCCCEE), Khartoum, Sudan, 16-18 January 2017.

6. Raja, P.S.; Geetha, B.G.; Raja, S. Detection of fuel theft in heavy vehicle. Int. J. Adv. Eng. Technol. 2016. E-ISSN 0976-3945. Available online: http:/ /www.makeitortakeit.in/documents/147/9IOT_and_Arduino_based_Vechicle_and_fuel_Theft_Detection_System1 (accessed on 16 August 2020).

7. Chandra, A.A.; Jannif, N.I.; Prakash, S.; Padiachy, V. Cloud Based Real-time Monitoring andControl of Diesel Generator using the IoT Technology. In Proceedings of the 2017 20th International Conference on Electrical Machines and Systems (ICEMS), Sydney, NSW, Australia, 11-14 August 2017. 